\title{
Assessing the progression of mild cognitive impairment to Alzheimer's disease: current trends and future directions
}

\author{
Larry G Brooks' and David A Loewenstein ${ }^{2,3 *}$
}

\begin{abstract}
With the advent of advances in biomarker detection and neuropsychological measurement, prospects have improved for identifying and tracking the progression of Alzheimer's disease (AD) from its earliest stages through dementia. While new diagnostic techniques have exciting implications for initiating treatment earlier in the disease process, much work remains to be done to optimize the contributions of the expanding range of tools at the disposal of researchers and clinicians. The present paper examines recent work in cerebrospinal fluid biomarkers, magnetic resonance imaging, positron emission tomography, neuropsychological measures, and functional assessment. The strengths and weaknesses of current methodologies are explored and discussed. It is concluded that AD from its mild cognitive impairment state through dementia represents a continuous process, and that progression over time can best be accomplished by interval-level variables. Biomarkers that are most sensitive to early AD may not be the most optimal for monitoring longitudinal change, and it is likely that multivariate models incorporating cognitive measures, functional variables and biomarker data will be the most fruitful avenues for future research.
\end{abstract}

\section{Introduction}

A hallmark feature of the National Institute of Neurological and Communicative Diseases and Stroke-Alzheimer's Disease and Related Disorders Association criteria for a

\footnotetext{
*Correspondence: dloewenstein@med.miami.edu

2Department of Psychiatry and Behavioral Sciences and Center on Aging, Miller School of Medicine, University of Miami, 1695 NW $9^{\text {th }}$ Avenue, Suite 300, Miami, FL 33136, USA

Full list of author information is available at the end of the article
}

clinical diagnosis of probable Alzheimer's disease (AD), first established over 25 years ago, was the requirement of a dementia syndrome. The clinician then proceeded to systematically rule out and exclude other neurological and/or medical conditions that might have accounted for the observed cognitive decline. This set of criteria as well as the Diagnostic and Statistical Manual of Mental Disorders (fourth edition) criteria for a dementia syndrome and probable $\mathrm{AD}$ [1] were designed to be conservative so that a neurodegenerative condition could not be established unless cognitive function was sufficiently compromised to interfere with an individual's social and/or occupational function.

Since AD probably develops many years before cognitive symptoms are manifest [2] and cognitive deficits are evident before the appearance of a full-blown dementia syndrome, increasing attention has been focused on mild cognitive impairment $(\mathrm{MCI})$ as an intermediary state between normal cognition and $\mathrm{AD}[3,4]$. The generally accepted criteria for $\mathrm{MCI}$ are the presence of a memory or other cognitive complaint by an individual or other knowledgeable informant, objective deficits on standardized objective cognitive tests and the lack of a dementia syndrome characterized by intact general intellectual function and no significant deficits in social and/or occupational function. As disease-modifying agents are developed, the best hope for prevention or cure lies in treating the disorder in its earliest stages before the brain is severely compromised by multisystem degeneration [5].

Efforts at earlier detection of $\mathrm{AD}$ face significant challenges in improving assessment of the earliest cognitive and neuropathological changes associated with early $\mathrm{AD}$, identifying those $\mathrm{MCI}$ cases that are most likely to progress over time, and gauging the progression of MCI to a clinical diagnosis of AD. This improvement requires assessment tools that are sensitive to subtle cognitive changes, as well as measures that are adequate in evaluating deterioration in cognitive abilities over time. Complicating efforts at early diagnosis are the fact that not all cases of MCI will progress to dementia, and 
that not all cases of dementia will eventually be diagnosed with AD. This is particularly true in epidemiological studies, where the reversion of MCI to non-MCI has been as high as $40 \%$ [6] - as opposed to the progression ranging from 10 to $15 \%$ in specialty memory disorders clinics and other clinical settings $[3,7]$.

The popular term regarding conversion from $\mathrm{MCI}$ to dementia of the $\mathrm{AD}$ type is probably a misnomer. If one has correctly identified underlying $\mathrm{AD}$ in a predementia phase, then progression to a clinical diagnosis of $\mathrm{AD}$ is merely dependent on the individual progressing to a particular threshold at which point there is sufficient cognitive and functional impairment to merit the diagnosis of a dementia syndrome (provided that the clinician can rule out other potential etiologies). In recent years, there has been increasing concern that $\mathrm{AD}$ is not being identified in its earlier stages because of a failure to emphasize the primary episodic memory deficit and abnormal biomarkers associated with the disorder, specifically volumetric magnetic resonance imaging (MRI), positron emission tomography (PET) neuroimaging, and cerebrospinal fluid (CSF) analysis of amyloid $\beta$ or tau proteins [8]. Furthermore, the delineation between $\mathrm{MCI}$ and dementia that is critical to a diagnosis of $\mathrm{AD}$ may vary as a function of experience and/or idiosyncratic thresholds of an individual clinician in judging whether an individual's cognitive impairment is significantly interfering with social and/or occupational function [9].

What follows is an examination of different types of measures that are sensitive to early $\mathrm{AD}$ in the MCI state, and perhaps at an earlier stage, and are most effective for tracking progression to a dementia state over time.

\section{Cognitive measures}

Despite the excitement about recent advances in the identification of AD-related biomarkers, neuropsychological assessment remains a critical component of evaluation to ensure a cognitive correlate of biomarker abnormalities and to assist in detecting and tracking progression of early AD. Neuropsychological evaluation provides both standardized and objective assessment of the hallmark feature of MCI and AD: the disturbance of memory and/or other cognitive functions - in particular, episodic memory deficits as manifested by impaired delayed recall [10], faster rate of forgetting [11], and problems with learning new information [12]. Deficits in delayed recall and other memory functions have been found to be predictive of cognitive decline in communitydwelling older subjects [13] and of progression of MCI to dementia [14].

Deficits in early AD, however, are not only limited to memory. Although memory dysfunction is typically the most common manifestation of early $\mathrm{AD}$, some cases first present with executive, language or visuospatial disturbances. It is widely accepted that memory impairment across multiple memory measures or a combination of deficits in memory and nonmemory measures have less reversion to normal and faster rates of progression to dementia than those with single amnestic or nonamnestic cognitive impairments [15]. This suggests that multiple cognitive impairments or severity of deficits in a single domain such as memory may be a proxy for the patient's stage of illness. As noted in the new proposed guidelines for MCI related to AD [16], serial cognitive assessments of an individual in the MCI stage of AD allows for the assessment of cognitive decline over time and enhances confidence in the progressive nature of the disorder and its underlying etiology. Techniques such as reliable change indices and consideration of practice effects are methods to measure meaningful change at an individual level, which can also be useful in analyzing the results of clinical trials [17].

In assessing the progression of mild cognitive impairment to $A D$, it is imperative that $M C I$ is correctly diagnosed and that these underlying cognitive impairments accurately reflect the underlying $\mathrm{AD}$ pathology. Current challenges in the cognitive assessment of MCI include: test selection, the availability of normative databases, and the effect of different base rates of MCI and $\mathrm{AD}$ in different settings; establishing cut-off points for impairment; and developing measures more sensitive to early $\mathrm{AD}$ while having sufficient specificity to distinguish between etiologically different conditions.

Methodologically, the lack of uniformity in the selection of neuropsychological measures and the use of different normative databases often make it challenging to compare study results across settings and internationally. Further, differential base rates of true underlying cognitive impairment or AD pathology in older adults presenting to specialty memory disorder clinics compared with a general medical practice or in epidemiological settings may affect the diagnostic accuracy of neuropsychological tests. In general, a low prevalence or base rate of true cognitive impairment in a particular setting tends to reduce the positive predictive value or the probablility that a positive test represents true impairment while false negatives will remain low. In contrast, when the base rates of true cognitive impairment are high, the positive predictive value is high but there is an increased probability that a negative test will not reflect a true absence of impairment.

Another challenge in cognitive assessment is the issue of cognitive reserve [18], which allows persons with diseased brains to use compensatory mechanisms that may mask overt manifestations of disease. Possible solutions to the problem of diagnosing cognitive impairment in highly intelligent people is to apply appropriate norms for these subgroups, to develop more cognitively 
challenging measures where compensation is more difficult or to employ test paradigms that allow withinsubject comparisons of different aspects of memory (some of which are particularly vulnerable to early manifestations of $\mathrm{AD}$ ).

Diagnostically, the lack of standardization in cut-off points employed to determine impairment also creates discrepancies in the literature, which affects the ability to compare studies examining progression to specific endpoints among different national and international research groups [19]. Many studies of amnestic mild cognitive impairment (aMCI) employ a 1.5 standard deviation cut-off point relative to age and educational norms on one or more memory measures, with the realization that as the number of tests increases, there is a tendency towards false positives [20]. Other studies recommend using multiple memory measures but require a cut-off point of 1.0 standard deviation below expected levels on at least two cognitive tests in the same cognitive domain [15]. In the current large ADNI-GO multisite neuroimaging study [21], provided that subjects meet clinical criteria for early MCI, educationally referenced scores on delayed paragraph recall at 0.5 to 1.0 standard deviation below expected levels are considered sufficient for inclusion as early aMCI. At the other extreme, an individual with objective memory impairment $\geq 3$ standard deviations below expected levels may still be classified as $\mathrm{MCI}$ if the clinician does not judge there to be sufficient impairments in social and/or occupational function to meet criteria for dementia. Indeed, in the new proposed criteria for $\mathrm{MCI}$ related to $\mathrm{AD}$ a range of impairment of 1.0 to 1.5 standard deviations below expected levels on tests is typically expected on neuropsychological tests [16], but this is not a requirement as more emphasis is placed on clinical history and examination. MCI as it is currently conceptualized therefore represents a wide range of individuals with varying severity of cognitive impairment. It naturally follows that the rate of progression to dementia, and an eventual AD state, may largely reflect the degree of initial disease severity as measured by cognitive measures.

Specific patterns of cognitive impairments may not be specific to one disease entity. Disorders such as AD, diffuse Lewy body disease, cerebrovascular disorders and frontotemporal dementia are generally thought to have characteristic cognitive presentations in the early stages of disease but there can be considerable overlap in cognitive performance across disease entities. This overlap problem is particularly salient in the two most common forms of dementia - AD and vascular dementia where meta-analytic studies have found a limited ability of cognitive tests to distinguish between groups [22]. In a study of autopsy-defined subjects with cerebrovascular disease and $\mathrm{AD}$, a majority of $\mathrm{AD}$ subjects exhibited a cognitive profile characterized by memory impairment but no reliable characteristic profile existed for cerebrovascular disease [23]. Another meta-analysis comparing $\mathrm{AD}$ with frontotemporal dementia showed significant differences between groups on multiple measures, but the considerable overlap between groups renders differential diagnosis in individual cases difficult [24]. Similarly, there is considerable heterogeneity among individuals that limits specificity in distinguishing between MCI of different etiologies [25].

Tracking progression from MCI to dementia and an eventual diagnosis of $\mathrm{AD}$ requires cognitive measures sensitive to change over time. Although measures such as the Alzheimer's Disease Assessment Scale (cognitive subscale) have been employed in a number of large-scale pharmacological studies of $\mathrm{AD}$, there may be insufficient sensitivity to change in early-stage MCI. For example, in the GEM study, the annual rate of change on the Alzheimer's Disease Assessment Scale (cognitive subscale) for MCI patients was considerably less than the degree of change considered clinically significant in $\mathrm{AD}$ trials [26].

While there is currently a plethora of memory tests available, list-learning tests have the dual advantages of multiple learning trials and delayed recall. Dubois and colleagues contend that increased encoding specificity at acquisition and assessed failure to benefit from cuing at recall are superior to episodic memory tests using free recall alone in identifying early cases of AD [8]. Indeed, it has been previously shown that a primary deficit in profiting from encoding cues at baseline and follow-up was superior to free recall and other traditional measures in detecting cognitive impairment [27]. Deficits on the MCT, a test of controlled learning and cued semantic recall, were recently uniquely sensitive and related to the presence of $\left[{ }^{11} \mathrm{C}\right]$ Pittsburgh compound $\mathrm{B}$ (PiB) on PET scans in community older people [27]. Our group has found that list-learning tests employing distractor tasks between acquisition trials and competing lists enhancing susceptibility to semantic interference both have excellent sensitivity for $\mathrm{MCI}$ and are predictive of progression from MCI to dementia [12,20]. The advantage of these aforementioned paradigms is that they target specific semantic memory processing deficits that may be specific to early $\mathrm{AD}$. Comparison of the individual's performances on different aspects of the same test seems well-suited to dealing with issues of high cognitive reserve. Although promising, future research is needed to determine the specificity of such findings to $\mathrm{AD}$ and their utility in serial assessments over time.

\section{Functional assessment in mild cognitive impairment}

An important concept in MCI has been the notion that functional activities of daily living should be intact [3]. 
Although a discussion of all available functional assessment instruments is beyond the scope of this paper, research has increasingly shown that subjects with a formal diagnosis of MCI frequently have functional impairments. In aMCI patients, Instrumental Activities of Daily Living measures at baseline independently predicted progression to AD 1 year later [28]. Similarly, MCI subjects who progressed to AD 1 year later presented as more impaired on financial capacity at baseline and had greater decline than nonprogressors [29]. A 3 -year longitudinal study of medical decision-making capacity showed that individuals with aMCI performed progressively worse in comprehending consent information as compared with their own baseline performance and with a control group [9].

Studies of the relationship between neuropsychological test performance and functional ability have linked Activities of Daily Living deficits and Instrumental Activities of Daily Living deficits to global cognitive impairment [30], executive function and attention [31], and task-specific neuropsychological deficits [32]. In most studies, however, neuropsychological measures have not explained the majority of the variability in functional measures, particularly in mildly impaired subjects. This lack of explanation consequently suggests there is something unique about informant-based observations of real-world behaviors or the subject's performance on performance-based tests that may not always be captured by neuropsychological tasks. A strength of informant report of cognitive deterioration is the ability to compare a subject's performance with premorbid functioning so that true decline can be measured. Although decline can be inferred by baseline neuropsychological testing, it cannot be proven in the absence of serial cognitive evaluation.

The Clinical Dementia Rating Scale (CDR) developed by John Morris was one of the first validated clinical instruments to identify individuals in a predementia state, and a CDR score of 0.5 became known to indicate the early stages of $\mathrm{AD}$ preceding dementia [33]. The CDR is included here as a functional assessment measure in that it combines objective cognitive testing with the clinical assessment of six different areas of daily function (memory, orientation, judgment, problem-solving, community affairs, and personal care) after an extensive interview with a knowledgeable informant. The CDR is therefore unique in relating cognitive deficits to realworld consequences in everyday life, and is a widely used tool for clinical assessment of disease with longstanding demonstrated utility in diagnosis [34] and prediction of disease progression [35]. In a number of studies, progression to dementia has been delineated by change from a global CDR of 0.5 (questionable dementia) to a global CDR of 1.0 (mild dementia) or higher [36,37]. The
CDR sum of boxes has been demonstrated as a particularly sensitive method of monitoring progression of cognitive impairment over time [38]. Change in CDR scores or change in CDR sum of boxes has been used as an outcome measure in studies assessing the utility of various techniques for predicting progression from $\mathrm{MCI}$ to AD, including CSF biomarkers [39], morphometry [39], functional MRI [40], amyloid burden [41], and 2-[ $\left.{ }^{18} \mathrm{~F}\right]$-fluoro-2-deoxy-D-glucose (FDG)-PET [42].

Taken together, this evidence shows there are functional impairments in the MCI stage of $\mathrm{AD}$ that progressively become worse until the clinician has decided the individual has reached the threshold at which they meet the criteria for dementia. Once this threshold is crossed, the person has not converted to AD but has merely progressed to a level of severity such that the cognitive deficits have a profound impact on the individual's life. Serial functional assessment is important, however, in that it is essential for tracking disease progression, developing optimal strategies for symptom management, and attempting to enhance quality of life.

\section{Biomarkers}

The recent criteria for MCI of Alzheimer's type set forth by the National Institute of Aging Alzheimer's Association workgroup propose that molecular biomarkers such as CSF $A \beta-42$, CSF tau/A $\beta-42$ ratio, $p$-tau/A $\beta-42$ ratio or amyloid load identified by imaging are most probably related to the underlying pathology of $\mathrm{AD}$ [16]. Topographic measures such as hypometabolism or hypoperfusion on PET or single-photon emission computed tomography or medial temporal lobe atrophy support the diagnosis of $\mathrm{AD}$, and may be particularly useful in monitoring disease progression.

\section{Cerebrospinal fluid proteins}

CSF biomarkers have been shown to differentiate between healthy controls and AD patients [43], and have utility in predicting progression from aMCI to $\mathrm{AD}$ [44] and from MCI to AD [45]. The CSF $A \beta-42 /$ tau ratio differentiated patients with subjective cognitive complaints, with non-aMCI, and with aMCI from healthy controls [46], was predictive of progression from aMCI to $\mathrm{AD}$ [46], was predictive of progression from controls to MCI [47], predicted cognitive decline in cognitively normal older adults [48], and differentiated between $\mathrm{AD}$ and vascular dementia [49]. Low $A \beta-42 / A \beta-40$ ratios predicted eventual development of MCI or AD at followup 3 to 7 years later among cognitively normal community volunteers [50]. A meta-analysis of CSF phosphorylated tau showed satisfactory clinical utility in diagnosing $\mathrm{MCI}$ and progression of MCI to dementia, but was less capable of differentiating $\mathrm{AD}$ from other types of dementia [51]. 
CSF biomarkers are additionally associated with a number of the cardinal features of AD. CSF proteins predict the rate of cognitive decline in AD [52], in mild $\mathrm{AD}$ [53], and in healthy older adults [54]. CSF biomarkers are related to hippocampal atrophy [55] and postmortem neuritic plaques [56]. The CSF A $\beta-42 /$ tau ratio also predicted the presence of postmortem neuritic plaques with a sensitivity of $91.6 \%$ and a specificity of $87.5 \%$ in a mixed population including AD, other dementia, and other neurologic disease [56]. In a more recent study, CSF amyloid was found in $90 \%$ of $\mathrm{AD}$ patients, in $72 \%$ of MCI patients, and in 36\% (a 6.88 increased risk in apolipoprotein E4 carriers) of cognitively normal older people. Furthermore, 100\% of subjects with MCI who progressed to AD and $94 \%$ of pathologically verified AD patients could be identified [57]. Despite impressive sensitivity, however, the specificity was limited; and given the predominance of $\mathrm{AD}$ patients in the sample, it is difficult to determine the ability of this biomarker to distinguish between etiologically distinct conditions.

Other studies have shown less promising results, such as the absence of a relationship between CSF proteins and disease progression [58]. CSF proteins were not associated with postmortem plaques and tangles in 50 AD patients [59]. A multisite study of CSF biomarkers demonstrated that although $A \beta-42$, $p$-tau, and total tau predicted progression from $\mathrm{MCI}$ to $\mathrm{AD}$, a receiveroperating characteristic curve analysis was only modestly accurate at 0.78 for $A \beta-42,0.76$ for $p$-tau, and 0.79 for total tau [60]. A meta-analysis found that CSF biomarkers were less sensitive than episodic memory scores in detecting preclinical AD [10]. Altogether, CSF biomarkers appear to have considerable promise in early detection of $\mathrm{AD}$ - but more work is required to optimize their contribution.

\section{Neuroimaging}

Given the prominence of the amyloid hypothesis of AD, the ability to detect $\beta$-amyloid accumulation in vivo in the brain has generated excitement about the possibility of earlier AD detection. PiB-PET imaging of amyloid deposition has been associated with cortical atrophy [61], glucose metabolism [62], CSF biomarkers [63], eventual development of $\mathrm{AD}$ in cognitively normal older adults [41], default mode network connectivity [64], CDR sum of boxes score [65], cognitive decline [61], and episodic memory [37]. Recent studies have shown that PiB may be useful in detecting preclinical AD [41,61] and in predicting the progression from $\mathrm{MCI}$ to $\mathrm{AD}$ [66]. PiBPET imaging is also being studied to determine its usefulness in distinguishing diagnostic categories [67], and has shown the ability to distinguish between aMCI and non-aMCI [68].
Although PiB-PET imaging techniques are correlated to many of the key aspects and biomarkers of $\mathrm{AD}$, there may be limitations to their usefulness. Most importantly, amyloid deposition has been found in a significant percentage of cognitively normal older subjects [69]. Further, a range of studies have failed to replicate associations between amyloid deposition and clinical measures [70], cognition [69], FDG-PET [71], and hippocampal atrophy in $\mathrm{AD}$ [69]. Cognitive reserve and the finding that amyloid appears well before cognitive symptoms may explain some of the discrepancies in the literature [27]. Also, PiB uptake appears to be nonspecific for AD, as it has been shown to be elevated in Parkinson's dementia [72] and in Lewy body disease [73].

In addition to measuring amyloid burden, FDG-PET imaging has been employed to study regional and global variations in cortical activity in AD progression. FDGPET hypometabolism has been associated with amyloid burden [62], CSF biomarkers [74], maternal history of AD [75], apolipoprotein E4 status in healthy adults [76], verbal memory test decline [77], memory test performance [78], and perceived memory loss [79]. Regional variations in glucose metabolism have also correlated with progression from pre-MCI to MCI [77] and from aMCI to AD [78]. Diagnostically, FDG-PET increases statistical power over cognitive measures [67] and has superior diagnostic sensitivity (0.84) and specificity (0.74) to an initial clinical evaluation [80]. FDG-PET successfully identified different metabolic patterns in $\mathrm{AD}$ and cerebrovascular disease [81] and assisted in distinguishing between AD and frontotemporal dementia [82].

In addition to PET imaging, longitudinal volumetric neuroimaging with MRI has identified brain regions that tend to manifest neuronal loss early in the course of MCI. Research has demonstrated changes in medial temporal lobe structures in subjects with MCI [83] or in subjects with aMCI who progress to dementia [84]. Other brain regions implicated in disease progression include the anterior and posterior cingulate gyrus, precunus, and frontal lobes [84]. Recent work has also investigated the utility of functional MRI to predict progression of cognitive decline in MCI [40]. Research has shown that there is a prodromal period in $\mathrm{AD}$ in which there is stable decline, followed by more rapid cognitive and structural changes in the 2 to 3 years prior to the expression of clinical symptomatology [85]. Similarly, Carlson and colleagues showed that rates of ventricular volume expansion are greater in subjects who go on to develop $\mathrm{MCI}$, and that the rate of expansion increases in the 2 to 3 years prior to clinical MCI diagnosis [86].

Taken together, CSF biomarkers, FDG-PET, and MRI studies have shown considerable promise in identifying early $\mathrm{AD}$ and monitoring the disease progression through the clinical stages to dementia. New techniques that 
allow visualization of amyloid deposition offer an exciting possibility of detection of disease in its earliest possible stages but may not be as useful as cognitive measures, imaging techniques or other biomarkers for monitoring changes in the brain that occur between the MCI and dementia stages of $\mathrm{AD}$. The use of these techniques also raises an important issue. Significant percentages of cognitively normal older people may have AD pathology but do not manifest cognitive symptoms during life [69], and many cases of MCI have non-AD pathology. Assessment tools with high specificity in early detection are needed to facilitate early intervention of AD. Despite the understandable excitement that biomarkers provide, it will be important to be appropriately cautious regarding the application of these new techniques to clinical care and practice until the techniques can be established as specific to AD [87].

\section{Conclusion}

While lauding a decade of efforts to delineate subclassifications of $\mathrm{AD}$, it is important to emphasize that $\mathrm{AD}$ remains a single disease entity throughout all its stages. Consequently, movement from stage to stage signifies disease progression on a continuum (which is not always linear), rather than a conversion from one entity to another. Nonetheless, efforts to differentiate disease stages have considerable utility, particularly in research, and it is imperative to establish greater uniformity in assessment, cut-off points, and diagnostic criteria to more meaningfully compare the results of national and international research efforts. The new proposed National Institute of Aging Alzheimer's Association guidelines for the diagnosis of $\mathrm{AD}$ recognize the need to identify preclinical AD as well as MCI due to AD [16]. These new criteria will undoubtedly stimulate the further research needed in the area.

Based on current evidence, we briefly summarize our views on how to best study the progression of deficits associated with the MCI stage of early $\mathrm{AD}$ as follows.

First, conversion to dementia has typically been used as a primary endpoint to judge treatment effects in $\mathrm{AD}$ although this may not be the optimal way to study progression in a disorder that falls on a continuum, particularly as attempts are made to treat the disorder in its earliest stages. Given their continuous nature, objective cognitive measures will probably be among the more useful measures for assessing $\mathrm{AD}$ progression and monitoring response to the earliest interventions.

Second, memory measures assessing learning over multiple trials with delayed recall are among the most powerful cognitive measures in early detection and monitoring of early $\mathrm{AD}$, but nonmemory measures particularly those tapping executive function, language and visual-spatial skills - should be employed in serial
This article is part of a review series on Prevention trials. Other articles in the series can be found online at http://alzres.com/series/ preventiontrials

assessment of MCI. In addition, ratings of cognitive and functional change - particularly those observed by skilled clinicians and knowledgeable informants over time - can provide critical information. Further development of newer paradigms that focus on encoding specificity, deficits in semantic memory processing, dysexecutive function, and the use of techniques such as reliable change analyses will be useful in detecting early impairment and gauging meaningful changes in performance over time.

Third, the presence of specific CSF biomarkers, the amyloid load in the brain, and specific patterns of brain hypometabolism or atrophy make it much more likely that cases of both early and later MCI represent early AD, which will be critical to the development of early clinical intervention studies. Further, serial assessment of these neuroimaging markers such as PET and MRI may have particular utility in assessing longitudinal change or response to intervention.

Finally, since each method provides unique information and variance, it is likely that a combination and statistical weighting of different biomarkers and neuropsychological tests across serial assessments will provide the most robust predictor at both the group and individual levels. For instance, combined FDG-PET and PiB-PET imaging has been shown capable of distinguishing between control, MCI, and $\mathrm{AD}$ subjects better than either technique in isolation [88]. Similarly, a recent study demonstrated that combined FDG-PET and episodic memory scores predicted progression from MCI to AD better than either measure alone [89].

Newly emerging technologies to study brain function have generated considerable enthusiasm. While sensitivity to early $\mathrm{AD}$ is critical, specificity to the neuropathology of the disorder and the ability to differentiate between different etiological conditions is critically important. Identifying the best combination of predictors of eventual clinical outcomes and the optimal means of utilizing these predictors are the most important challenges for future research.

\section{Abbreviations \\ $A D$, Alzheimer's disease; aMCl, amnestic mild cognitive impairment; $C D R$ Clinical Dementia Rating Scale; CSF, cerebrospinal fluid; FDG, 2-[18 F]-fluoro-2- deoxy-D-glucose; $\mathrm{MCl}$, mild cognitive impairment; $\mathrm{MRI}$, magnetic resonance imaging; PET, positron emission tomography; $\mathrm{PiB},\left[{ }^{11} \mathrm{C}\right]$ Pittsburgh compound $\mathrm{B}$.}

\section{Competing interests}

The authors declare that they have no competing interests.

\section{Author details}

'Department of Rehabilitation Medicine, Miller School of Medicine - University of Miami, P.O. Box 016960 (C-206), Miami, FL 33101, USA. ${ }^{2}$ Department of 
Psychiatry and Behavioral Sciences and Center on Aging, Miller School of Medicine, University of Miami, 1695 NW $9^{\text {th }}$ Avenue, Suite 300, Miami, FL 33136, USA. ${ }^{3}$ Wien Center for Alzheimer's Disease and Memory Disorders, Mount Sinai Medical Center, 4300 Alton Road, Miami Beach, FL 33140, USA

Published: 29 September 2010

\section{References}

1. American Psychiatric Association Task Force on DSM-IV: Diagnostic and Statistical Manual of Mental Disorders: DSM-IV. 4th edition. Washington, DC: American Psychiatric Association; 1994.

2. Braak H, Braak E: Neuropathological stageing of Alzheimer-related changes. Acta Neuropathol 1991, 82:239-259.

3. Petersen RC, Smith GE, Waring SC, Ivnik RJ, Tangalos EG, Kokmen E: Mild cognitive impairment: clinical characterization and outcome. Arch Neurol 1999, 56:303-308

4. Winblad B, Palmer K, Kivipelto M, Jelic V, Fratiglioni L, Wahlund LO, Nordberg A, Backman L, Albert M, Almkvist O, Arai H, Basun H, Blennow K, de Leon M, DeCarli C, Erkinjuntti T, Giacobini E, Graff C, Hardy J, Jack C, Jorm A, Ritchie K, van Duijn C, Visser P, Petersen RC: Mild cognitive impairment - beyond controversies, towards a consensus: report of the International Working Group on Mild Cognitive Impairment. J Intern Med 2004, 256:240-246.

5. Cummings $\mathrm{JL}$, Doody R, Clark C: Disease-modifying therapies for Alzheimer disease: challenges to early intervention. Neurology 2007, 69:1622-1634

6. Larrieu S, Letenneur L, Orgogozo JM, Fabrigoule C, Amieva H, Le Carret N, Barberger-Gateau P, Dartigues JF: Incidence and outcome of mild cognitive impairment in a population-based prospective cohort. Neurology 2002, 59:1594-1599

7. Ritchie K, Artero S, Touchon J: Classification criteria for mild cognitive impairment: a population-based validation study. Neurology 2001, 56:37-42.

8. Dubois B, Feldman HH, Jacova C, Dekosky ST, Barberger-Gateau P, Cummings J, Delacourte A, Galasko D, Gauthier S, Jicha G, Meguro K, O'Brien J, Pasquier F, Robert P, Rossor M, Salloway S, Stern Y, Visser PJ, Scheltens P: Research criteria for the diagnosis of Alzheimer's disease: revising the NINCDS-ADRDA criteria. Lancet Neurol 2007, 6:734-746

9. Okonkwo OC, Griffith HR, Copeland JN, Belue K, Lanza S, Zamrini EY, Harrell LE, Brockington JC, Clark D, Raman R, Marson DC: Medical decision-making capacity in mild cognitive impairment: a 3-year longitudinal study. Neurology 2008, 71:1474-1480

10. Schmand B, Huizenga HM, van Gool WA: Meta-analysis of CSF and MRI biomarkers for detecting preclinical Alzheimer's disease. Psychol Med 2010, 40:135-145

11. Vanderploeg RD, Yuspeh RL, Schinka JA: Differential episodic and semantic memory performance in Alzheimer's disease and vascular dementias. J Int Neuropsychol Soc 2001, 7:563-573

12. Loewenstein DA, Acevedo A, Luis C, Crum T, Barker WW, Duara R: Semantic interference deficits and the detection of mild Alzheimer's disease and mild cognitive impairment without dementia. J Int Neuropsychol Soc 2004, 10:91-100.

13. Petersen RC: Mild cognitive impairment: transition between aging and Alzheimer's disease. Neurologia 2000, 15:93-101.

14. Rabin LA, Pare N, Saykin AJ, Brown MJ, Wishart HA, Flashman LA, Santulli RB: Differential memory test sensitivity for diagnosing amnestic mild cognitive impairment and predicting conversion to Alzheimer's disease. Neuropsychol Dev Cogn B Aging Neuropsychol Cogn 2009, 16:357-376.

15. Jak AJ, Bondi MW, Delano-Wood L, Wierenga C, Corey-Bloom J, Salmon DP, Delis DC: Quantification of five neuropsychological approaches to defining mild cognitive impairment. Am J Geriatr Psychiatry 2009, 17:368-375.

16. Phelps T, Thies W, McKhann G, Albert M, Sperling R, DeKosky S: Redefining Alzheimer's disease symposium. In Alzheimer's Association International Conference on Alzheimer's Disease 2010: Focused Topic Sessions: Redefining Alzheimer's Disease. Presented July 13, 2010. Honolulu, HI. 2010. http://www. alz.org/research/diagnostic criteria/

17. Stein J, Luppa M, Brahler E, Konig HH, Riedel-Heller SG: The assessment of changes in cognitive functioning: reliable change indices for neuropsychological instruments in the elderly - a systematic review. Dement Geriatr Cogn Disord 2010, 29:275-286.

18. Stern Y: Cognitive reserve and Alzheimer disease. Alzheimer Dis Assoc Disord 2006, 20:569-S74.

19. Luis CA, Loewenstein DA, Acevedo A, Barker WW, Duara R: Mild cognitive impairment: directions for future research. Neurology 2003, 61:438-444

20. Loewenstein DA, Acevedo A, Ownby R, Agron J, Barker WW, Isaacson R, Strauman S, Duara R: Using different memory cutoffs to assess mild cognitive impairment. Am J Geriatr Psychiatry 2006, 14:911-919.

21. Aisen PS, Petersen RC, Donohue MC, Gamst A, Raman R, Thomas RG, Walter $S$, Trojanowski JQ, Shaw LM, Beckett LA, Jack CR Jr, Jagust W, Toga AW, Saykin AJ, Morris JC, Green RC, Weiner MW: Clinical Core of the Alzheimer's Disease Neuroimaging Initiative: progress and plans. Alzheimers Dement 2010, 6:239-246

22. Mathias JL, Burke J: Cognitive functioning in Alzheimer's and vascular dementia: a meta-analysis. Neuropsychology 2009, 23:411-423.

23. Reed BR, Mungas DM, Kramer JH, Ellis W, Vinters HV, Zarow C, Jagust WJ, Chui HC: Profiles of neuropsychological impairment in autopsy-defined Alzheimer's disease and cerebrovascular disease. Brain 2007, 130:731-739.

24. Hutchinson AD, Mathias JL: Neuropsychological deficits in frontotemporal dementia and Alzheimer's disease: a meta-analytic review. J Neurol Neurosurg Psychiatry 2007, 78:917-928.

25. Loewenstein DA, Acevedo A, Agron J, Issacson R, Strauman S, Crocco E, Barker WW, Duara R: Cognitive profiles in Alzheimer's disease and in mild cognitive impairment of different etiologies. Dement Geriatr Cogn Disord 2006, 21:309-315

26. Snitz BE, O'Meara ES, Carlson MC, Arnold AM, Ives DG, Rapp SR, Saxton J, Lopez OL, Dunn LO, Sink KM, DeKosky ST: Ginkgo biloba for preventing cognitive decline in older adults: a randomized trial. JAMA 2009, 302:2663-2670.

27. Rentz DM, Locascio JJ, Becker JA, Moran EK, Eng E, Buckner RL, Sperling RA, Johnson KA: Cognition, reserve, and amyloid deposition in normal aging. Ann Neurol 2010, 67:353-364.

28. Rozzini L, Chilovi BV, Conti M, Bertoletti E, Delrio I, Trabucchi M, Padovani A: Conversion of amnestic mild cognitive impairment to dementia of Alzheimer type is independent to memory deterioration. Int J Geriatr Psychiatry 2007, 22:1217-1222.

29. Triebel KL, Martin R, Griffith HR, Marceaux J, Okonkwo OC, Harrell L, Clark D, Brockington J, Bartolucci A, Marson DC: Declining financial capacity in mild cognitive impairment: a 1-year longitudinal study. Neurology 2009, 73:928-934.

30. Zanetti O, Frisoni GB, Rozzini L, Bianchetti A, Trabucchi M: Validity of direct assessment of functional status as a tool for measuring Alzheimer's disease severity. Age Ageing 1998, 27:615-622.

31. Okonkwo OC, Wadley VG, Griffith HR, Ball K, Marson DC: Cognitive correlates of financial abilities in mild cognitive impairment. J Am Geriatr Soc 2006, 54:1745-1750.

32. Farias ST, Harrell E, Neumann C, Houtz A: The relationship between neuropsychological performance and daily functioning in individuals with Alzheimer's disease: ecological validity of neuropsychological tests. Arch Clin Neuropsychol 2003, 18:655-672.

33. Morris JC: The Clinical Dementia Rating (CDR): current version and scoring rules. Neurology 1993, 43:2412-2414.

34. O'Bryant SE, Lacritz LH, Hall J, Waring SC, Chan W, Khodr ZG, Massman PJ, Hobson V, Cullum CM: Validation of the new interpretive guidelines for the clinical dementia rating scale sum of boxes score in the national Alzheimer's coordinating center database. Arch Neurol 2010, 67:746-749.

35. Dickerson BC, Sperling RA, Hyman BT, Albert MS, Blacker D: Clinical prediction of Alzheimer disease dementia across the spectrum of mild cognitive impairment. Arch Gen Psychiatry 2007, 64:1443-1450.

36. Ganguli M, Chang CC, Snitz BE, Saxton JA, Vanderbilt J, Lee CW: Prevalence of mild cognitive impairment by multiple classifications: the MonongahelaYoughiogheny Healthy Aging Team (MYHAT) project. Am J Geriatr Psychiatry 2010, 18:674-683.

37. Mormino EC, Kluth JT, Madison CM, Rabinovici GD, Baker SL, Miller BL, Koeppe RA, Mathis CA, Weiner MW, Jagust WJ: Episodic memory loss is related to hippocampal-mediated $\beta$-amyloid deposition in elderly subjects. Brain 2009, 132:1310-1323.

38. O'Bryant SE, Waring SC, Cullum CM, Hall J, Lacritz L, Massman PJ, Lupo PJ, Reisch JS, Doody R: Staging dementia using Clinical Dementia Rating scale sum of boxes scores: a Texas Alzheimer's research consortium study. Arch Neurol 2008, 65:1091-1095.

39. Fjell AM, Walhovd KB, Fennema-Notestine C, McEvoy LK, Hagler DJ, Holland D, Brewer JB, Dale AM: CSF biomarkers in prediction of cerebral and clinical change in mild cognitive impairment and Alzheimer's disease. J Neurosci 2010, 30:2088-2101. 
40. Miller SL, Fenstermacher E, Bates J, Blacker D, Sperling RA, Dickerson BC: Hippocampal activation in adults with mild cognitive impairment predicts subsequent cognitive decline. J Neurol Neurosurg Psychiatry 2008, 79:630-635.

41. Morris JC, Roe CM, Grant EA, Head D, Storandt M, Goate AM, Fagan AM, Holtzman DM, Mintun MA: Pittsburgh compound B imaging and prediction of progression from cognitive normality to symptomatic Alzheimer disease. Arch Neurol 2009, 66:1469-1475.

42. Ishii H, Ishikawa H, Meguro K, Tashiro M, Yamaquchi S: Decreased cortical glucose metabolism in converters from CDR 0.5 to Alzheimer's disease in a community: the Osaki-Tajiri Project. Int Psychogeriatr 2009, 21:148-156.

43. Buchhave P, Blennow K, Zetterberg H, Stomrud E, Londos E, Andreasen N, Minthon L, Hansson O: Longitudinal study of CSF biomarkers in patients with Alzheimer's disease. PLoS One 2009, 4:e6294.

44. Vemuri P, Wiste HJ, Weigand SD, Shaw LM, Trojanowski JQ, Weiner MW, Knopman DS, Petersen RC, Jack CR, Jr: MRI and CSF biomarkers in normal, $\mathrm{MCl}$, and AD subjects: diagnostic discrimination and cognitive correlations. Neurology 2009, 73:287-293.

45. Diniz BS, Pinto Junior JA, Forlenza OV: Do CSF total tau, phosphorylated tau, and $\beta$-amyloid 42 help to predict progression of mild cognitive impairment to Alzheimer's disease? A systematic review and metaanalysis of the literature. World J Biol Psychiatry 2008, 9:172-182.

46. Visser PJ, Verhey F, Knol DL, Scheltens P, Wahlund LO, Freund-Levi Y, Tsolaki M, Minthon L, Wallin AK, Hampel H, Burger K, Pirttila T, Soininen H, Rikkert MO, Verbeek MM, Spiru L, Blennow K: Prevalence and prognostic value of CSF markers of Alzheimer's disease pathology in patients with subjective cognitive impairment or mild cognitive impairment in the DESCRIPA study: a prospective cohort study. Lancet Neurol 2009, 8:619-627.

47. Li G, Sokal I, Quinn JF, Leverenz JB, Brodey M, Schellenberg GD, Kaye JA, Raskind MA, Zhang J, Peskind ER, Montine TJ: CSF tau/Aß42 ratio for increased risk of mild cognitive impairment: a follow-up study. Neurology 2007, 69:631-639.

48. Fagan AM, Roe CM, Xiong C, Mintun MA, Morris JC, Holtzman DM: Cerebrospinal fluid tau/ $\beta$-amyloid(42) ratio as a prediction of cognitive decline in nondemented older adults. Arch Neurol 2007, 64:343-349.

49. de Jong D, Jansen RW, Kremer BP, Verbeek MM: Cerebrospinal fluid amyloid $\beta 42 /$ phosphorylated tau ratio discriminates between Alzheimer's disease and vascular dementia. J Gerontol A Biol Sci Med Sci 2006, 61:755-758.

50. Graff-Radford NR, Crook JE, Lucas J, Boeve BF, Knopman DS, Ivnik RJ, Smith GE, Younkin LH, Petersen RC, Younkin SG: Association of low plasma A $342 /$ $A \beta 40$ ratios with increased imminent risk for mild cognitive impairment and Alzheimer disease. Arch Neurol 2007 ,64:354-362.

51. Mitchell AJ: CSF phosphorylated tau in the diagnosis and prognosis of mild cognitive impairment and Alzheimer's disease: a meta-analysis of 51 studies. J Neurol Neurosurg Psychiatry 2009, 80:966-975.

52. Jagust WJ, Landau SM, Shaw LM, Trojanowski JQ, Koeppe RA, Reiman EM, Foster NL, Petersen RC, Weiner MW, Price JC, Mathis CA: Relationships between biomarkers in aging and dementia. Neurology 2009, 73:1193-1199.

53. Snider BJ, Fagan AM, Roe C, Shah AR, Grant EA, Xiong C, Morris JC, Holtzman DM: Cerebrospinal fluid biomarkers and rate of cognitive decline in very mild dementia of the Alzheimer type. Arch Neurol 2009, 66:638-645.

54. Stomrud E, Hansson O, Zetterberg H, Blennow K, Minthon L, Londos E: Correlation of longitudinal cerebrospinal fluid biomarkers with cognitive decline in healthy older adults. Arch Neurol 2010, 67:217-223.

55. Henneman WJ, Vrenken H, Barnes J, Sluimer IC, Verwey NA, Blankenstein MA, Klein M, Fox NC, Scheltens P, Barkhof F, van der Flier WM: Baseline CSF p-tau levels independently predict progression of hippocampal atrophy in Alzheimer disease. Neurology 2009, 73:935-940.

56. Tapiola T, Alafuzoff I, Herukka SK, Parkkinen L, Hartikainen P, Soininen $H$, Pirttila T: Cerebrospinal fluid $\beta$-amyloid 42 and tau proteins as biomarkers of Alzheimer-type pathologic changes in the brain. Arch Neurol 2009, 66:382-389.

57. De Meyer G, Shapiro F, Vanderstichele H, Vanmechelen E, Engelborghs S, De Deyn PP, Coart E, Hansson O, Minthon L, Zetterberg H, Blennow K, Shaw L, Trojanowski JQ: Diagnosis-independent Alzheimer disease biomarker signature in cognitively normal elderly people. Arch Neurol 2010, 67:949-956.

58. Bouwman FH, van der Flier WM, Schoonenboom NS, van Elk EJ, Kok A, Rijmen F, Blankenstein MA, Scheltens P: Longitudinal changes of CSF biomarkers in memory clinic patients. Neurology 2007, 69:1006-1011

59. Engelborghs S, Sleegers K, Cras P, Brouwers N, Serneels S, De Leenheir E,
Martin JJ, Vanmechelen E, Van Broeckhoven C, De Deyn PP: No association of CSF biomarkers with $\mathrm{APOE} \varepsilon 4$, plaque and tangle burden in definite Alzheimer's disease. Brain 2007, 130:2320-2326.

60. Mattsson N, Zetterberg H, Hansson O, Andreasen N, Parnetti L, Jonsson M, Herukka SK, van der Flier WM, Blankenstein MA, Ewers M, Rich K, Kaiser E, Verbeek, M, Tsolaki M, Mulugeta E, Rosen E, Aarsland D, Visser PJ, Schroder J, Marcusson J, de Leon M, Hampel H, Scheltens P, Pirttila T, Wallin A, Jonhagen ME, Minthon L, Winblad B, Blennow K: CSF biomarkers and incipient Alzheimer disease in patients with mild cognitive impairment. JAMA 2009, 302:385-393.

61. Storandt M, Mintun MA, Head D, Morris JC: Cognitive decline and brain volume loss as signatures of cerebral amyloid-beta peptide deposition identified with Pittsburgh compound B: cognitive decline associated with A $\beta$ deposition. Arch Neurol 2009, 66:1476-1481.

62. Cohen AD, Price JC, Weissfeld LA, James J, Rosario BL, Bi W, Nebes RD, Saxton JA, Snitz BE, Aizenstein HA, Wolk DA, Dekosky ST, Mathis CA, Klunk WE: Basal cerebral metabolism may modulate the cognitive effects of $A \beta$ in mild cognitive impairment: an example of brain reserve. J Neurosci 2009, 29:14770-14778.

63. Fagan AM, Mintun MA, Shah AR, Aldea P, Roe CM, Mach RH, Marcus D, Morris $J C$, Holtzman DM: Cerebrospinal fluid tau and ptau(181) increase with cortical amyloid deposition in cognitively normal individuals: implications for future clinical trials of Alzheimer's disease. EMBO Mol Med 2009, 1:371-380.

64. Hedden T, Van Dijk KR, Becker JA, Mehta A, Sperling RA, Johnson KA, Buckner RL: Disruption of functional connectivity in clinically normal older adults harboring amyloid burden. J Neurosci 2009, 29:12686-12694

65. Grimmer T, Henriksen G, Wester HJ, Forstl H, Klunk WE, Mathis CA, Kurz A, Drzezga A: Clinical severity of Alzheimer's disease is associated with PIB uptake in PET. Neurobiol Aging 2009, 30:1902-1909.

66. Wolk DA, Price JC, Saxton JA, Snitz BE, James JA, Lopez OL, Aizenstein HJ, Cohen AD, Weissfeld LA, Mathis CA, Klunk WE, De-Kosky ST: Amyloid imaging in mild cognitive impairment subtypes. Ann Neurol 2009, 65:557-568.

67. Jagust WJ, Bandy D, Chen K, Foster NL, Landau SM, Mathis CA, Price JC, Reiman EM, Skovronsky D, Koeppe RA: The Alzheimer's Disease Neuroimaging Initiative positron emission tomography core. Alzheimers Dement 2010, 6:221-229.

68. Lowe VJ, Kemp BJ, Jack CR, Jr, Senjem M, Weigand S, Shiung M, Smith G, Knopman D, Boeve B, Mullan B, Petersen RC: Comparison of ${ }^{18} \mathrm{~F}-\mathrm{FDG}$ and PiB PET in cognitive impairment. J Nucl Med 2009, 50:878-886.

69. Rowe CC, Ellis KA, Rimajova M, Bourgeat P, Pike KE, Jones G, Fripp J, TochonDanguy H, Morandeau L, O'Keefe G, Price R, Raniga P, Robins P, Acosta O, Lenzo N, Szoeke C, Salvado O, Head R, Martins R, Masters CL, Ames D, Villemagne VL: Amyloid imaging results from the Australian Imaging, Biomarkers and Lifestyle (AIBL) study of aging. Neurobiol Aging 2010, 31:1275-1283

70. Jack CR, Jr, Lowe VJ, Weigand SD, Wiste HJ, Senjem ML, Knopman DS, Shiung MM, Gunter JL, Boeve BF, Kemp BJ, Weiner M, Petersen RC: Serial PIB and MRI in normal, mild cognitive impairment and Alzheimer's disease: implications for sequence of pathological events in Alzheimer's disease. Brain 2009, 132:1355-1365.

71. Furst AJ, Rabinovici GD, Rostomian AH, Steed T, Alkalay A, Racine C, Miller BL, Jagust WJ: Cognition, glucose metabolism and amyloid burden in Alzheimer's disease. Neurobiol Aging 2010, in press.

72. Burack MA, Hartlein J, Flores HP, Taylor-Reinwald L, Perlmutter JS, Cairns NJ: In vivo amyloid imaging in autopsy-confirmed Parkinson disease with dementia. Neurology 2010, 74:77-84.

73. Gomperts SN, Rentz DM, Moran E, Becker JA, Locascio JJ, KlunkWE, Mathis CA, Elmaleh DR, Shoup T, Fischman AJ, Hyman BT, Growdon JH, Johnson KA: Imaging amyloid deposition in Lewy body diseases. Neurology 2008, 71:903-910.

74. Petrie EC, Cross DJ, Galasko D, Schellenberg GD, Raskind MA, Peskind ER, Minoshima S: Preclinical evidence of Alzheimer changes: convergent cerebrospinal fluid biomarker and fluorodeoxyglucose positron emission tomography findings. Arch Neurol 2009, 66:632-637.

75. Mosconi L, Mistur R, Switalski R, Brys M, Glodzik L, Rich K, Pirraglia E, Tsui W, De Santi S, de Leon MJ: Declining brain glucose metabolism in normal individuals with a maternal history of Alzheimer disease. Neurology 2009, 72:513-520.

76. Langbaum JB, Chen K, Caselli RJ, Lee W, Reschke C, Bandy D, Alexander GE, Burns CM, Kaszniak AW, Reeder SA, Corneveaux JJ, Allen AN, Pruzin J, 
Huentelman MJ, Fleisher AS, Reiman EM: Hypometabolism in Alzheimeraffected brain regions in cognitively healthy Latino individuals carrying the apolipoprotein E \&4 allele. Arch Neurol 2010, 67:462-468.

77. Caselli RJ, Chen K, Lee W, Alexander GE, Reiman EM: Correlating cerebral hypometabolism with future memory decline in subsequent converters to amnestic pre-mild cognitive impairment. Arch Neurol 2008, 65:1231-1236.

78. Anchisi D, Borroni B, Franceschi M, Kerrouche N, Kalbe E, Beuthien-Beumann B, Cappa S, Lenz O, Ludecke S, Marcone A, Mielke R, Ortelli P, Padovani A, Pelati O, Pupi A, Scarpini E, Weisenbach S, Herholz K, Salmon E, HolthoffV, Sorbi S, Fazio F, Perani D: Heterogeneity of brain glucose metabolism in mild cognitive impairment and clinical progression to Alzheimer disease. Arch Neurol 2005, 62:1728-1733.

79. Ercoli L, Siddarth P, Huang SC, Miller K, Bookheimer SY, Wright BC, Phelps ME, Small G: Perceived loss of memory ability and cerebral metabolic decline in persons with the apolipoprotein E-IV genetic risk for Alzheimer disease. Arch Gen Psychiatry 2006, 63:442-448.

80. Jagust W, Reed B, Mungas D, Ellis W, Decarli C: What does fluorodeoxyglucose PET imaging add to a clinical diagnosis of dementia? Neurology 2007, 69:871-877.

81. Kuczynski B, Reed B, Mungas D, Weiner M, Chui HC, Jagust W: Cognitive and anatomic contributions of metabolic decline in Alzheimer disease and cerebrovascular disease. Arch Neurol 2008, 65:650-655.

82. Foster NL, Heidebrink JL, Clark CM, Jagust WJ, Arnold SE, Barbas NR, DeCarli CS, Turner RS, Koeppe RA, Higdon R, Minoshima S: FDG-PET improves accuracy in distinguishing frontotemporal dementia and Alzheimer's disease. Brain 2007, 130:2616-2635.

83. McDonald CR, McEvoy LK, Gharapetian L, Fennema-Notestine C, Hagler DJ, Jr, Holland D, Koyama A, Brewer JB, Dale AM: Regional rates of neocortical atrophy from normal aging to early Alzheimer disease. Neurology 2009, 73:457-465.

84. Whitwell JL, Shiung MM, Przybelski SA, Weigand SD, Knopman DS, Boeve BF, Petersen RC, Jack CR, Jr: MRI patterns of atrophy associated with progression to AD in amnestic mild cognitive impairment. Neurology 2008 , 70:512-520.

85. Johnson DK, Storandt M, Morris JC, Galvin JE: Longitudinal study of the transition from healthy aging to Alzheimer disease. Arch Neurol 2009, 66:1254-1259.

86. Carlson NE, Moore MM, Dame A, Howieson D, Silbert LC, Quinn JF, Kaye JA: Trajectories of brain loss in aging and the development of cognitive impairment. Neurology 2008, 70:828-833.

87. Rockwood K: Con: Can biomarkers be gold standards in Alzheimer's disease? Alzheimers Res Ther 2010, 2:16

88. Devanand DP, Mikhno A, Pelton GH, Cuasay K, Pradhaban G, Kumar JS, Upton N, Lai R, Gunn RN, Libri V, Liu X, Heertum RV, Mann JJ, Parsey RV: Pittsburgh compound $B\left({ }^{11} \mathrm{C}-\mathrm{PIB}\right)$ and fluorodeoxyglucose $\left({ }^{18} \mathrm{~F}-\mathrm{FDG}\right) \mathrm{PET}$ in patients with Alzheimer disease, mild cognitive impairment, and healthy controls. $J$ Geriatr Psychiatry Neurol 2010, 23:185-198.

89. Landau SM, Harvey D, Madison CM, Reiman EM, Foster NL, Aisen PS, Petersen RC, Shaw LM, Trojanowski JQ, Jack CR Jr, Weiner MW, Jagust WJ: Comparing predictors of conversion and decline in mild cognitive impairment. Neurology 2010, 75:230-238.

doi:10.1186/alzrt52

Cite this article as: Brooks $L G$, Loewenstein DA: Assessing the progression of mild cognitive impairment to Alzheimer's disease: current trends and future directions. Alzheimer's Research \& Therapy 2010, 2:28. 